\title{
1 Ancient symbiosis confers desiccation resistance to stored grain pest beetles
}

2

3 Tobias Engl ${ }^{1,2,}$, , Nadia Eberl ${ }^{1+}$, Carla Gorse $^{1+}$, Theresa Krüger ${ }^{1+}$, Thorsten H. P. Schmidt ${ }^{2}$, Rudy Plarre ${ }^{3}$, Cornel 4 Adler $^{4}$, Martin Kaltenpoth ${ }^{1,2}$

$5{ }^{1}$ Max-Planck-Institute of Chemical Ecology, Research Group Insect Symbiosis, Hans-Knoell-Straße 8, 07745

6 Jena, Germany

$7 \quad{ }^{2}$ current address: Johannes Gutenberg-University Mainz, Department of Evolutionary Ecology, Johann-

8 Joachim-Becherweg 13, 55128 Mainz, Germany

$9 \quad{ }^{3}$ Federal Institute for Material Research and Testing, Unter den Eichen 87, 12205 Berlin, Germany

104 Julius-Kühn-Institute, Federal Research Centre for Cultivated Plants, Institute for Ecological Chemistry,

11 Plant Analysis and Stored Product Protection, Königin-Luise-Str. 19, 14195 Berlin, Germany

$12+$ contributed equally

$13 *$ Corresponding author: tengl@uni-mainz.de 


\section{Abstract}

Microbial symbionts of insects provide a range of ecological traits to their hosts that are beneficial in the context of biotic interactions. However, little is known about insect symbiont-mediated adaptation to the abiotic environment, e.g. temperature and humidity. Here we report on an ancient ( 400 Mya) clade of intracellular, bacteriome-located Bacteroidetes symbionts that are associated withgrain and wood pest beetles of the phylogenetically distant families Silvanidae and Bostrichidae. In the saw-toothed grain beetle Oryzaephilus surinamensis, we demonstrate that the symbionts affect cuticle thickness, melanization and hydrocarbon profile, enhancing desiccation resistance and thereby strongly improving fitness under dry conditions. Together with earlier observations on symbiont contributions to cuticle biosynthesis in weevils, our findings indicate that convergent acquisitions of bacterial mutualists represented key adaptations enabling diverse pest beetle groups to survive and proliferate under the low ambient humidities that characterize dry grain storage facilities.

\section{Introduction}

Microbial mutualists are a major driving force of evolution (Klepzig et al., 2009), as they confer a variety of ecological benefits to their host (Feldhaar, 2011, Oliver and Martinez, 2014). In insects, numerous studies yielded evidence for symbiont-provided benefits in the context of biotic interactions, particularly through the supplementation, degradation, or detoxification of the diet (Moran, 2006, Douglas, 2009, van den Bosch and Welte, 2017) or by defending the host against natural enemies (Florez et al., 2015). However, comparatively little is known about symbiont-mediated adaptations to the abiotic environment. Notably, several studies reported on symbionts that enhance resistance of insects to high temperatures (Russell and Moran, 2006, Montllor et al., 2002, Brumin et al., 2011). In most of these cases, however, facultative secondary symbionts ameliorate heat susceptibility of primary obligate symbionts rather than directly altering the host physiology and thereby extending the viable temperature range (Wernegreen, 2012, Corbin et al., 2017). Nevertheless, under selective conditions for heat resistance, during hot summers in desert sites, the abundance of protective, secondary symbionts was indeed found to increase in pea aphids, presumably reflecting adaptation to higher temperatures (Harmon et al., 2009).

Stored grain pest insects profit from an excess of food but face the challenge of low environmental humidity that is maintained in storage facilities to prevent the growth of mould fungi (Hagstrum et al., 1996). Several groups of beetles independently managed to invade the same ecological niche of stored grain and dried plant products despite the considerably lower humidity compared to the ancestral habitat associated with a 
fungivorous or saprophagous state of living under bark (Crowson, 1981, Hunt et al., 2007). Most of these groups were described to harbor facultative intracellular bacterial symbionts. Weevils of the genus Sitophilus engage in a symbiosis with the $\gamma$-proteobacterium Sodalis pierantonius, and the silvanid saw-toothed grain beetle Oryzaephilus surinamensis and several bostrichid beetles are associated with as yet unidentified symbionts (Koch, 1931, Mansour, 1934, Koch, 1936a, Buchner, 1965, Nardon and Grenier, 1988, Heddi et al., 1999, Kleespies et al., 2001). In all cases, the symbionts can be experimentally depleted or removed without disrupting the hosts' life cycle in laboratory settings, and some populations of $O$. surinamensis were even found to contain aposymbiotic individuals in the field (Koch, 1936b, Huger, 1956, Vigneron et al., 2014). However, S. pierantonius was shown to provide precursors for cuticle biosynthesis that are especially important during beetle development, and symbiont cells are actively degraded in adults (Vigneron et al., 2014). Symbiont-free (aposymbiotic) weevil populations suffer from a lower growth rate due to higher mortality and reduced fecundity, but are viable and able to reproduce (Nardon and Grenier, 1988). The symbionts of both $O$. surinamensis and Rhizopertha dominica are likewise not obligate, and past studies were unable to establish any evidence for a physiological or ecological benefit of their presence (Koch, 1956, Huger, 1956).

Here, we investigate the hypothesis that engaging in mutualistic associations with bacteria represents a (pre)adaptation in several beetle families to exploit stored grain products as a food source. To that end, we characterized the intracellular symbionts of five bostrichid and three silvanid species of grain and wood pest beetles, revealing a shared and ancient symbiosis related to the intracellular Bacteriodetes symbionts of cicadas (Sulcia), cockroaches and termites (Blattabacterium). For the saw-toothed grain beetle O.surinamensis, experimental symbiont elimination resulted in reduced cuticle melanization and thickness as well as increased cuticular hydrocarbon biosynthesis upon drought stress. Concordantly, aposymbiotic beetles suffered from lower population growth rates and were more susceptible to desiccation and droughtinflicted mortality, indicating that the symbiosis enhances desiccation resistance and thereby likely played, besides in other important functions, like the defense against natural enemies, a key role for the adaptation of phylogenetically diverse beetles to conditions of low ambient humidity in mature grain and especially stored grain facilities.

\section{Results}

Bostrichid and silvanid pest beetles harbor ancient Sulcia-like intracellular symbionts 
By PCR amplification, cloning and sequencing of the bacterial 16S rRNA gene, we characterized the symbionts associated with five bostrichid beetles (Lyctus brunneus, Rhizopertha dominica, Prostephanus truncatus, Dinoderus bifoveolatus and Dinoderus porcellus) and three silvanid beetles (Ahasverus advena, Oryzaephilus mercator and Oryzaephilus surinamensis). While L. brunneus feeds on seasoned hard wood, all others are serious pests of diverse stored grain products. Surprisingly, despite the phylogenetic distance of Bostrichidae and Silvanidae (about 240 mya, see Hunt et al., 2007), the symbionts of all eight species were assigned to the same clade of Bacteroidetes bacteria that also contained Sulcia muelleri, the symbionts of Auchenorrhyncha, and Blattabacterium, the symbionts of cockroaches and some termites (Fig. 1, Supplemental Fig. 1). While the three silvanid species and two of the bostrichids ( $R$. dominica and $P$. truncatus) contained a single symbiont, L. brunneus and the two Dinoderus species additionally displayed a second, more basally branching clade of symbionts (Fig. 1). Based on diagnostic PCRs, the derived and in all species maintained symbiont could be detected in 68\%-99\% (Supplemental Table 2) of tested adult beetles except $A$. advena, whereas the ancestral symbiont only associated with Lyctus and Dinoderus was detected in 68\% -90\%. In total, $95 \%-100 \%$ of the tested individuals were positive for at least one of both symbionts. In $O$. surinamensis and $R$. dominica, the degradation of symbionts in old individuals (particularly in males) has been reported (Huger, 1956), probably accounting for the low apparent infection frequencies across host species. Infection rates estimated by diagnostic PCR and Fluorescence in situ hybridization (FISH) in A. advena were with $30 \%$ considerably lower $(\mathrm{N}=10)$. Due to rare and low levels of infections (Fig. 2d) symbionts in A. advena were probably formerly not detected (Buchner, 1965). Consistenlty, despite being usually also considered as a stored grain pest, A.advena actually feeds on fungal infestations of grain, requires the addition of yeast extract in artificial grain diets and also relatively high environmental humidities of 70\% (Thomas and Leschen, 2009).

A phylogenetic dating analysis based on the partial symbiont 16S rRNA gene of $\sim 1250 \mathrm{bp}$ and two calibration points, the origin of the cicada-Sulcia symbiosis (260-280Mya; Moran et al., 2005) and the cockroachBlattabacterium symbiosis (150-300Mya; Patino-Navarrete et al., 2013), revealed an ancient origin of the clade of Bacteroidetes endosymbionts 494 Mya ago (Fig1, Supplemental Fig 1 and Supplemental Table 3). The mutualistic Bacteroidetes group comprising Blattabacteria, the beetle symbionts and Sulcia dates back around 394 Mya, with the split of the ancestral beetle symbiont clade and the split between Sulcia and the other beetle symbionts around 355Mya ago and the split of the Oryzaephilus and bostrichid symbionts around 331 Mya ago (Fig1, Supplemental Fig 1 and Supplemental Table 3). Different nucleotide substitution models had little impact on node ages with a mean node age for all endosymbionts varying between 489-503 Mya, and the mutualistic symbionts between 404-414 Mya, whereas strict clock models resulted in younger node ages (423-432 Mya and 384-392 Mya, respectively, see Supplemental Table 3). Omitting one calibration point 
shifted the divergence times to a considerably earlier time of 593 Mya, if only the origin of Blattabacterium was included, and to 474 Mya with only the origin of Sulcia included (Supplemental Table 3).

The bacterial symbionts were all located intracellularly, in bacteriomes located between gut, fat body and reproductive organs, but without direct connection to any of these tissues. While the Silvanid beetles contained two pairs of bacteriomes, both with the same single symbiont strain (Fig. 2a-d; see also Koch, 1936a), R. dominica and $P$. truncatus contained only one bacteriome pair with a single strain (Fig. $2 \mathrm{e}+\mathrm{f}$ ). In contrast, both Dinoderus species contained one pair of bacteriomes for each symbiont strain, which were anatomically separated from each other (Fig. $2 g+h$ ). L. brunneus harbored a pair of bacteriomes, each composed of a central bacteriome containing the ancestral symbiont strain surrounded by three bacteriomes harboring the derived symbiont strain (Fig. 2i+j; see also Koch, 1936a).

\section{Symbiont association is not obligate for $\boldsymbol{O}$. surinamensis}

As described previously, the $O$. surinamensis symbiont titers could be reduced by either heat or tetracycline treatment (Koch, 1936b, Huger, 1956). Treatment of adult beetles over three months with tetracycline resulted in a complete and stable elimination of the symbiont, while heat treatment only reduced symbiont titers (Supplemental Fig. 2). In the tetracycline treatment group, the native symbiont could neither be detected by quantitative PCR (Supplemental Fig. 2a) nor by FISH (16 eggs and 8 adults tested per time point, $100 \%$ lacked a symbiont in the treatment group, whereas $100 \%$ in the control group showed infection). Although the qPCRs occasionally resulted in off-target amplification in the absence of the native symbiont, none of the amplification products in the tetracycline-treated group matched the melting profile of the native symbiont amplicon (Supplemental Fig. 2a). In contrast, the offspring (eggs) of beetles that were exposed to $36^{\circ} \mathrm{C}$ as either adults or larvae showed slightly, but not significantly lower symbiont titers (Mann-Whitney-U tests; heat treated larvae vs. control $U=30, N=10$ each, $p=0.243$, heat treated adults vs. controls $U=101, N=30$ and 10, p=0.269; Supplemental Fig. 2b). In the next generation, symbionts were significantly reduced and often completely absent (Mann-Whitney-U test, F2 of heat treated adults vs control, $U=10.5, N=10$ each, p=0.003; Supplemental Fig. 2b), but less consistently so than in the tetracyclin treatment group.

Due to the successful elimination of symbionts by tetracycline treatment, the offspring of tetracycline treated beetles were maintained in a continuous laboratory culture over two years to perform all following experiments. Despite overall good performance of aposymbiotic cultures under optimal growth conditions of 
test, $U=154, p<0.001$, Supplemental Fig. 3a) and a significantly lower population growth of aposymbiotic beetles (exact 2-sided Mann-Whitney-U test, $U=30, p=0.004$, Supplemental Fig. 3b).

\section{Symbionts contribute to cuticle thickness and melanization in 0 . surinamensis}

Melanization of the cuticle increases its physical strength and contributes to desiccation resistance (Gibbs and Rajpurohit, 2010). Given the observed impact of symbiont elimination on cuticle melanization, we set out to assess the contribution of the $O$. surinamensis symbiont to cuticle formation and melanization in more detail, by exposing replicate symbiotic and aposymbiotic populations to dry $(30-40 \% \mathrm{RH})$ and humid $(60 \% \mathrm{RH})$ conditions. In adult beetles, both symbiont absence and reduced environmental humidity significantly reduced cuticle melanization (Table1, Fig. 3a) and cuticle thickness (Table1, Fig. 3b) with both a thinner endoand exocuticle (Table1, Supplemental Fig. 4a+b). Aposymbiotic adults exhibited overall a less melanized and on average $26 \%$ thinner cuticle than their symbiotic counterparts. In $4^{\text {th }}$ instar larvae, symbiont absence, but not the humidity regime, resulted in a significant reduction in cuticle thickness by about 20\% (Table1, Supplemental Fig. 4c).

\section{Effect of symbionts on the epicuticular hydrocarbon profile}

By adapting their cuticular hydrocarbon $(\mathrm{CHC})$ profile, insects including $O$. surinamensis can rapidly change the water permeability of their epicuticle (Howard et al., 1995, Gibbs and Rajpurohit, 2010). We exposed adult beetles from all four treatments (full factorial design of dry and moist, symbiotic and aposymbiotic) to severe desiccation stress (one day at $<2 \% \mathrm{RH}$ ) or not (control) and measured their respective $\mathrm{CHC}$ profiles. Symbiont presence and environmental humidity during rearing had a significant influence on the total amount of $\mathrm{CHCs}$, with symbiont elimination and dry conditions resulting in an increased amount of CHCs (Table1). While acute drought stress alone did not affect CHC amounts (Table1), the interaction with symbiont status did, with aposymbiotic beetles applying more CHCs to their cuticle under both chronic and acute desiccation stress (Table1, Fig 4a). In addition, symbiont absence and long term exposure to low humidity significantly increased the proportion of unsaturated hydrocarbons (Table1, $p<0.001$ ), and acute desiccation stress increased the proportion of unsaturated hydrocarbons in beetles adapted to low humidity, but decreased it for beetles adapted to high humidity (Table1, Fig. 4b). Furthermore, symbiont absence itself and its interaction with environmental humidity also affected the average chain length of CHCs on the cuticle with aposymbiotic beetles carrying shorter chain $\mathrm{CHCs}$, which is even enhanced under low humidity (Table1, Fig. 
167

168

169

170

171

172

173

174

175

176

177

178

179

180

181

182

183

184

185

186

187

188

189

190

191

192

193

194

195

4c), whereas neither long-term low humidity per se nor acute desiccation stress affected CHC chain length (Table1, Fig 4c). These results demonstrate that aposymbiotic beetles perceive desiccation stress significantly more strongly than symbiotic beetles, especially if they were already kept under low humidity, and mount a physiological response to improve their epicuticular properties, as higher amounts of hydrocarbons provide a better evaporation protection. Shorter and less saturated hydrocarbons are generally considered to offer less protection against desiccation. However these conclusens are derived by studying the behavior of $\mathrm{CHC}$ mixtures at different temperatures, not at a fixed temperature with varying humidities (Gibbs and Rajpurohit, 2010). Accordingly, beetles without symbionts and under chronic, low humidity seem not to be able to keep the potentially more protective composition of their $\mathrm{CHCs}$, but rather rely on the protective effect of a thicker hydrocarbon layer, whereas symbiotic beetles reared in a more humid environment are able to shift their $\mathrm{CHC}$ profile to a more favourable composition under acute desiccation stress.

\section{Symbionts confer desiccation resistance to 0 . surinamensis}

In order to test whether the observed symbiont-mediated changes in cuticular thickness, melanization, and $\mathrm{CHC}$ composition affect desiccation resistance in $O$. surinamensis, we measured water loss and mortality of symbiotic and aposymbiotic beetles under desiccation stress. Indeed, aposymbiotic beetles reared at high or low humidity desiccated faster than their symbiotic counterparts (Table1, Fig. 5a; measured as proportional decrease in weight as beetle dry mass differed between treatments; see Supplemental Fig. 5). Concordantly, symbiont-free beetles also exhibited higher mortality upon acute drought stress, independent of the humidity they experienced during development (Cox Mixed-Effect Model, N=400 (8 replicates with 50 individuals per treatment), Table1, Fig. 5b). Similarly, survival from oviposition until emergence of adults was significantly lower in the absence of symbionts under low humidity ( $\chi^{2}$ homogeneity test at $30 \% \mathrm{RH}: 10.5 \%$ for aposymbiotic beetles, $\mathrm{N}=114$, vs $27.5 \%$ for symbiotic beetles, $\mathrm{N}=40, \chi^{2}=6.71, \mathrm{p}=0.013$ ), but not at high humidity ( $\chi^{2}$ homogeneity test at $60 \% \mathrm{RH}: 31.4 \%$ for aposymbiotic beetles, $\mathrm{N}=296$ vs $41.7 \%$ for symbiotic beetles, $\left.N=103, \chi^{2}=3.63, p=0.057\right)$. The differential susceptibility to desiccation was also reflected in the beetles' population growth over three months, with a significant influence of symbiont absence, ambient humidity as well as their interaction (Table1, Fig. 6).

\section{Discussion}


We showed that grain pest beetles in the beetle families Bostrichidae and Silvanidae engage in a symbiotic association with a group of Bacteroidetes bacteria that is closely related to Sulcia and Blattabacterium, the obligate nutritional mutualists of cicadas and cockroaches, respectively. However, in contrast to these (Lo et al., 2003, Takiya et al., 2006), the beetle symbiont 16S rRNA sequences revealed multiple acquisition, exchange and/or loss events, and the bacterial partners exhibited higher sequence divergences, indicating older associations and/or faster evolutionary rates than the Sulcia and Blattabacterium associations (Silva and Santos-Garcia, 2015). The common ancestor of Blattabacterium, Sulcia and the symbionts of the bostrichid and silvanid beetles was estimated to have lived around 394 Mya, predating the evolution of the beetles (Coleoptera) (Hunt et al., 2007). Considering that the common ancestor of Aucchenorrhyncha, Blattodea, Silvanidae and Bostrichidae existed around 380 to 390 Mya and gave rise to all holometabolous and most hemimetabolous insects (Misof et al., 2014), an ancient infection with the Bacteriodetes symbiont and subsequent losses in all but these four taxa seems to be an unlikely scenario. The more parsimonious explanation, especially considering the estimated age of the Bostrichidae ( 150Mya) and Silvanidae ( 180Mya; Hunt et al. 2007) involves at least six independent acquisition events (one in Aucchenorrhyncha, one in Blattodea, two in Silvanidae, and two in Bostrichidae) (Fig. 1 and Supplemental Fig. 1) and is reminiscent of the repeated acquisition of symbionts from a few clades of intracellular gamma-proteobacteria across diverse insect taxa (Husnik et al., 2011). Possibly, particular clades of bacteria were adapted to an insectassociated (possibly parasitic) lifestyle and - akin to extant Wolbachia infections - successfully spread through mixed vertical and horizontal transmission, but only those associations evolving towards mutual benefits proved to be stable over evolutionary timescales, resulting in the patchy distribution we observe today. Supporting this hypothesis, a basal clade of the bacteroidetes endosymbionts actually consists of three species that are described as male-killing endosymbionts in different ladybug beetles (Fig.1; Hurst et al., 1997, Hurst et al., 1999).

Within the bostrichid-Bacteroidetes association, we discovered three cases of multipartite symbioses with two different strains of the same bacterial clade, located in different bacteriome organs or compartments. While co-obligate symbionts have been described repeatedly across sap-feeding Hemiptera, they are usually co-localized in adjacent bacteriocytes to facilitate exchange of metabolic products or intermediates for jointly synthesized products (McCutcheon and von Dohlen, 2011, Wu et al., 2006). Alternatively, they are intermixed in the same bacteriocytes, as is the case in the fragmented Hodgkinia genomes in several cicada species (Van Leuven et al., 2014, Campbell et al., 2015). Interestingly, some of the Bostrichid species seem to have lost their ancestral symbiont, a theory already formulated by Huger (1956) who also occasionally observed the formation of additional, uninfected bacteriomes in $R$. dominica. This raises not only the question of the 
individual contribution of the single strains, but also the physiological and especially ecological consequence of symbiont acquisition, replacement or loss events for the respective beetle groups (Joy, 2013, Sudakaran et al., 2015, Sudakaran et al., 2017). Ancestrally, both groups of beetles inhabit rather humid environments. While Bostrichid beetles are described to inhabit and feed on sapwood, dying or dead trees, Silvanid beetles feed presumably on fungal detritivores of decomposing wood (Hunt et al., 2007, Thomas and Leschen, 2009). Finally, while the ecological niches of the investigated beetles are all characterized by low humidity, they differ widely in the available nutrient composition of their diet. Dry wood inhabited by the genus Lyctus probably represents the resource that is poorest in nitrogen (Hoadley, 1998); dried fruit and roots as preferred by Dinoderus spp. may be similarly unbalanced (Nations, 1990), whereas the germ tissue of different grains may contain sufficient nitrogen sources (Souci et al., 2009), which could have contributed to the loss of the basal symbiont lineage in those beetles. The insect cuticle is in general composed of chitin fibrils - a polymer of $\mathrm{N}$-acetyl-glucosamine, which is synthesized from glucose, glutamine and acetylcoenzyme A (Muthukrishnan et al., 2012) - in a complex with proteins (Hackman, 1974). The outer layer of the cuticle, the exocuticle, can be melanized and sclerotized and thereby becomes harder, darker and supposedly more water proof (Hackman, 1974, Gibbs and Rajpurohit, 2010). The fact, that, unlike in S. oryzae (Vigneron et al., 2014), the thickness of both endo- and exocuticle of $O$. surinamensis is reduced in the absence of the symbiont, suggests a more general contribution of nutrients than specifically Dopa or a similar precursor for cuticle melanization and sclerotization (Klein et al., 2016). Thus, nutritional benefits provided by Bacteriodetes symbionts might likely reach beyond individual amino acids or their precursors for cuticle melanization as in S. oryzae (Vigneron et al., 2014) to nitrogen recycling and essential amino acid and vitamin provisioning, as in cockroaches and the Auchenorrhyncha (Sabree et al., 2009, McCutcheon and Moran, 2010) or in carpenter ants (Gil et al., 2003, Degnan et al., 2005) and Nardonella harboring weevils (Kuriwada et al., 2010, Hosokawa et al., 2015). The individual contributions and interactions between the symbiont strains are interesting topics for future studies, especially given the facultative nature of the intracellular symbiosis and possibility for experimental manipulation of symbiont infection status.

In addition to identifying an ancient group of symbiotic Sulcia-related bacteria in diverse grain and wood pest beetles, we demonstrated an ecological benefit in the saw-toothed grain beetle 0 . surinamensis conferred by their non-obligate, yet prevalent, intracellular symbiont. By supporting cuticle synthesis, the bacteria confer desiccation resistance to their host, which constitutes a significant fitness benefit for the beetles, particularly under the dry conditions that characterize their anthropogenic habitat of granaries and other storage facilities 
similar manner (Heddi et al., 1999, Vigneron et al., 2014) and may hence contribute to drought tolerance. Likewise, carpenter ants of the genus Camponotus and the invasive ant Cardiocondyla obscurior evolved symbioses with the $\mathrm{Y}$-proteobacteria Blochmannia and Candidatus Westeberhardia cardiocondylae, respectively, that support cuticle melanization through the synthesis of essential amino acids or tyrosine precursors, respectively (Blochmannia, de Souza et al., 2011, Candidatus Westeberhardia, Klein et al., 2016). However, in which way these ants benefit from enhanced cuticle melanization remains unclear. Ants as well as beetles my generally benefit from a thicker and harder cuticle as a first line of defense against many natural enemies, like predators, parasitoids and pathogens. For the grain beetles, we hypothesize that the symbioses families to independently invade their niches of originally individual items of dried grain, fruit and wood, but proved to be especially advantageous to invade recent, anthropogenic stores of dry grain and fruit, as well as seasoned wood.

\section{Materials \& Methods}

\section{Insect cultures}

O. surinamensis, A. advena, $R$. dominica, $P$. truncatus, $D$. bifoveolatus, and $D$. porcellus insect cultures were obtained from the Julius-Kühn-Institute / Federal Research Centre for Cultivated Plants (Berlin, Germany), 0 . mercator from Fera Science Ltd (Darlington, UK) and L. brunneus from the Federal Institute for Material Research and Testing (Berlin, Germany). Continuous symbiotic and aposymbiotic (see below) O. surinamensis cultures were maintained in $1.8 \mathrm{~L}$ plastic containers, filled with $50 \mathrm{~g}$ oat flakes, at $30^{\circ} \mathrm{C}$ and ambient humidity between $40 \%$ and $60 \%$ in the dark.

\section{DNA extraction, 16s rDNA cloning and sequencing}

Total DNA was isolated individually from 25-30 adults per species using the Epicentre MasterPure ${ }^{\mathrm{TM}}$ Complete DNA and RNA Purification Kit (Illumina Inc., Madison, Winsconsin, USA).

Total 16s rDNA was amplified from 5-12 DNA extracts per species using universal eubacterial primers fD1 and rP2 (Welsburg et al. 1991). Reaction mixtures for PCR amplification consisted of $6.4 \mu$ l distilled water, $1.25 \mu l$ PCR Buffer, $0.25 \mu \mathrm{IgCl}_{2}, 1.5 \mu \mathrm{l}$ dNTPs, $1 \mu \mathrm{l}$ of each primer (each $\left.10 \mathrm{pmol} / \mu \mathrm{l}\right), 0.1 \mu \mathrm{l}$ Taq polymerase $(5 \mathrm{U} / \mu \mathrm{l})$ 
by 30 cycles of $95^{\circ} \mathrm{C}, 60^{\circ} \mathrm{C}$, and $72^{\circ} \mathrm{C}$ for 40 s each, and a subsequent elongation step at $72^{\circ} \mathrm{C}$ for $10 \mathrm{~min}$. PCR products were purified with the Analytik Jena innuPREP PCRpure Kit (Jena, Germany).

291

292

293

294

295

296

297

298

299

300

301

302

303

304

305

306

307

308

309

310

311

312

313

314

315

316

317

318

319

Bacterial 16S rRNA amplicons from five individuals per beetle species were cloned with a pSC-A-amp/kan vector (Strata Clone PCR Cloning Kit, Agilent Technologies, Santa Clara, California, USA) into Escherichia coli K12. Vector insertion sequences of successfully transformed colonies were amplified by another PCR using the flanking primer pair M13_fwd and M13_rev. The PCR parameters and purification were identical as described above, except that an annealing temperature of $65^{\circ} \mathrm{C}$ was used, and entire cells from clone colonies were added to the PCR reaction mix as template. Bidirectional Sanger sequencing was performed in house to obtain the full sequence of the amplified 16S fragments using the M13_fwd/rev primers.

\section{Infection frequencies}

Diagnostic PCRs were conducted to assess symbiont infection frequencies in all eight insect species. Specific oligonucleotides (Supplemental Table 1) were designed based on an alignment of Sulcia muelleri, Blattabacterium sp. and free-living Bacteriodetes 16S rDNA sequences. Specificity of the primer sequences for Bacteriodetes was assessed in silico using the Ribosomal Database Project 16S rDNA collection (Cole et al., 2014). Specificity was further tested by trying to amplify fragments from DNA extracts of the beetle species that should not carry the focal symbiont as well as European firebug Pyrrhocoris apterus and European beewolf Philanthus triangulum guts DNA extracts that similarly are known to lack Bacteroidetes bacteria.

\section{Phylogenetic inference}

Beetle symbiont 16S rDNA sequences were aligned to representative Sulcia muelleri, Blattabacterium and free living Bacteriodetes 16S rDNA sequences obtained from the NCBI database, using the SILVA algorithm (Quast et al., 2013, Yilmaz et al., 2014) . A maximum-likelihood phylogenetic tree was reconstructed with PHYML (Guindon and Gascuel, 2003) as implemented in Geneious Pro 9.1.5 (Drummond AJ, 2011), using the GTR model with uniform substitution rates per site. The initial tree for the heuristic search was obtained automatically by applying Neighbour-Joining and BioNJ algorithms to a matrix of pairwise distances estimated using the Maximum Composite Likelihood (MCL) approach, and then selecting the topology with superior log likelihood value. Bootstrap values were obtained from 10,000 replicates. A second tree was reconstructed by Bayesian inference applying a GTR $+G+I$ model using MrBayes 3.2 (Huelsenbeck et al., 2001, Huelsenbeck and Ronquist, 2001, Ronquist and Huelsenbeck, 2003). The analysis ran for 2,000,000 generations, with trees sampled every 1,000 generations. After confirming that split frequencies converged to less than 0.01 , we used a "Burnin" of 20\%. Both trees were visualized with FigTree (http://tree.bio.ed.ac.uk/software/figtree/). 


\section{Phylogenetic dating}

Divergence time estimations were inferred using BEAST v1.8.4. MCMC analyses (Drummond A. J. and Rambaut, 2007) with HKY, GTR and TN93 nucleotide substitution models (empirical or estimated base frequencies, various site heterogeneity models [none, $G, I+G])$. Analyses were conducted under a strict clock (using a single rate of sequence evolution across the phylogeny) and an uncorrelated lognormal relaxed clock model (allowing variable substitution rates; Drummond A. J. et al., 2006). In each analysis, 100 million steps were performed, and trees were sampled every 100,000 steps. The phylogenetic tree from the Bayesian inference analysis (see previous section) was used a fixed input tree in all analyses. Nucleotide substitution priors were determined with jmodeltest v2.1.9 (Guindon and Gascuel, 2003, Darriba et al., 2012). The age of the cockroach-Blattabacterium (normal distribution, mean $\pm S D=220 \pm 25$; Patino-Navarrete et al., 2013) and cicada-Sulcia muelleri (normal distribution, mean $\pm=270 \pm 3.5$; Moran et al., 2005) symbioses were used as calibration points for the dating analyses. with 100 steps logged every 1 million generations. The analysis with the best fitting model $(G T R+I+G)$ was repeated twice with only one of both calibration points. Models were evaluated using Tracer v1.6 (http://beast.bio.ed.ac.uk/Tracer), consensus trees were generated with TreeAnnotator v1.8.4 (Drummond A. J. and Rambaut, 2007) using a burnin of $10 \%$ and a posterior probability limit of 0.3 and visualized with FigTree v1.4.2 (http://tree.bio.ed.ac.uk/software/figtree/).

\section{Fluorescence in situ hybridization (FISH)}

342

Whole mount FISH was performed on O.surinamensis larvae, standard FISH on squashed, fixed eggs and on sections of adult beetles. Fresh or frozen beetle eggs were fixed by slightly squashing them on a glass slide and incubation for three minutes in $70 \%$ ethanol and another 3 minutes in $96 \%$ ethanol. Whole larvae, pupae and adults were briefly washed in diethylether and fixed for at least three days in $4 \%$ paraformaldehyde in PBS. Adults were then dehydrated and embedded in Technovit 8100 (Heraeus-Kulzer, Germany), and 10 $\mu \mathrm{m}$ sections were cut on a microtome Microtome (Microm HM355S, Leica, Germany) and mounted on diagnostic microscope slides.

Probes were designed based on specific primers (see Supplemental Table 1) and were labelled with the cyanine dyes $\mathrm{Cy} 3$ or Cy5. Sections of adults and whole eggs were covered with hybridization buffer containing $0.9 \mathrm{M} \mathrm{NaCl}, 0.02 \mathrm{M}$ Tris $/ \mathrm{HCl}, 0.01 \% \mathrm{SDS}, 0.5 \mu \mathrm{M}$ of each labelled oligonucleotide probe and $5 \mu \mathrm{g} / \mathrm{ml}$ of the 
general DNA stain DAPI. Hybridization was performed at $50^{\circ} \mathrm{C}$ for $60 \mathrm{~min}$. The samples were subsequently washed twice with washing buffer consisting of $0.1 \mathrm{M} \mathrm{NaCl}, 0.02 \mathrm{M}$ Tris/ $\mathrm{HCl}, 5, \mathrm{mM}$ EDTA and $0.01 \%$ SDS and incubated at $50^{\circ} \mathrm{C}$ for $20 \mathrm{~min}$ in washing buffer, followed by a washing step with distilled water. After drying, the sections or eggs were covered with Vectashield (Vector Laboratories, Curlingham, CA, USA) and a cover slip.

Whole mount fish was performed by staining entire larvae at $50^{\circ} \mathrm{C}$ overnight in the same hybridization buffer. Afterwards, samples were washed twice for two hours with pre-warmed washing buffer at $50^{\circ} \mathrm{C}$ and twice for $20 \mathrm{~min}$ with distilled water at room temperature, before mounting on 2-well slides and covering with Vectarshield for fluorescence microscopy. ). Images were acquired with an Axiolmager Z2 equipped with an Apotome.2 (Zeiss, Germany) and a SOLA light engine LED light source (Lumencor, OR, USA) under 200-400x magnification with the Z-stack option.

\section{Elimination of O.surinamensis symbionts}

In order to obtain symbiont-free $O$. surinamensis, 150 adults were kept for three months on oat flakes that were soaked in a tetracycline solution (30mg tetracycline hydrochloride / g oat flakes; Sigma-Aldrich, Germany) and dried at $60^{\circ} \mathrm{C}$. 200 adult offspring individuals of these beetles were then transferred back to a standard oat flake diet. A control group experienced the same conditions except that the tetracycline was omitted from the oat flake soaking step. Efficiency of symbiont elimination was verified by qPCR of both eggs and adults immediately after the tetracycline treatment as well as three and twelve months later, respectively. For all time points, eggs were also collected and squashed onto slides, fixed for 10min with $95 \%$ and $70 \%$ ethanol subjected to FISH as described above to verify symbiont absence. Furthermore, eight female adults of the F2-F3 generation (three months after the tetracycline treatment) were sectioned and subjected to FISH as described above.

Quantitative PCRs were carried out in $25 \mu \mathrm{L}$ reactions using the Qiagen QuantiTect-SYBR-Green-PCR mix (Qiagen, Venlo, The Netherlands), including $0.5 \mu \mathrm{M}$ of each primer and $1 \mu \mathrm{L}$ template DNA. To compensate for host developmental stage and size as well as DNA extraction efficiency, all qPCR samples were additionally subjected to a PCR with primers targeting the host 28S rRNA gene, and the resulting delta Ct values were used for relative quantification of bacterial 16S rRNA copies per host 28S rRNA copy (Pfaffl, 2001).

\section{Physiological response and fitness of symbiotic and aposymbiotic $O$. surinamensis lines}


382 Eight symbiotic and aposymbiotic $O$. surinamensis populations were founded from one year old aposymbiotic 383 and symbiotic control cultures and reared at $30-40 \% \mathrm{RH}$ and $60 \% \mathrm{RH}$ in a full-factorial design to measure cuticle thickness of $4^{\text {th }}$ instar larvae, melanization and thickness of the adult cuticle, cuticular hydrocarbon profiles of adults, desiccation resistance measured as water loss, as well as survival and population growth. For each replicate, 50 beetles were transferred to a box with oat flakes $(20 \mathrm{~g})$ that were pre-conditioned for one week to the experimental conditions. Replicate populations were kept at $28^{\circ} \mathrm{C}$ and the two different humidity conditions in the dark for three months. In parallel to the replicate treatments, individual females from the basic cultures of all four treatments were separated into 12 well plates, eggs collected and the offspring individually reared in 48-well plates provided with one oat flake and incubated under above mentioned conditions. Survival until emergence of adults was monitored daily to assess mortality during development.

To evaluate the impact of humidity and symbiont elimination on cuticle melanisation, we determined the inverse red values (Vigneron et al., 2014) of 24 beetles from each treatment group. Photographs were taken with a Sony NEX 5 camera coupled to a Motic dissection stereoscope (Wetzlar, Germany) under identical conditions. Average red values were measured within an elliptic area covering the ventral thorax with the histogram tool in ImageJ 1.50a (Rasband, 1997-2016) and transformed into the inverse red values. To measure cuticle thickness, 9-14 adult beetles and ten $4^{\text {th }}$ instar larvae per treatment group were fixated in $4 \%$ paraformaldehyde in PBS. These beetles, as well as larvae from collected after three months from the eight replicate populations were embedded in epoxy resin (Epon_812 substitute, Sigma-Aldrich, Germany) and $1 \mu \mathrm{m}$ cross sections of the thorax next to the second pair of legs were cut on a Microtome (Microm HM355S, Leica, Germany) with a diamond blade and mounted on silanized glass slides with Histokitt (Roth, Germany). Images to measure cuticle diameter were taken with an Axiolmager Z2 (Zeiss, Germany) under 200x magnification and differential interference contrast. Mean cuticle diameter was measured for one randomly chosen dorsal, ventral and lateral point, respectively, with the ZEN software distance tool (Zeiss, Germany). Living adult beetles of each population were counted manually after three months to measure population growth. Immediately after counting, two batches of 50 beetles of each population were transferred to separate containers that were either empty or provided with three dried oat flakes, to measure water loss and survival, respectively. At the same time, two samples of 30 beetles each were transferred to $1.4 \mathrm{~mL}$ glass vials to measure cuticular hydrocarbon profiles before and after desiccation stress, respectively. 
414

415

416

417

418

419

420

421

422

423

424

425

426

427

428

429

430

431

432

433

434

435

436

437

438

439

440

441

442

443

444

chamber was thereby reduced to below $2 \% \mathrm{RH}$ within $30 \mathrm{~min}$ after closing the box. One group of containers with 50 beetles was weighed daily to measure water loss keeping dead beetles in the container. From the other group, dead beetles were counted and removed daily to monitor survival.

To assess the impact of low humidity, symbiont elimination, and acute desiccation stress on CHC profiles, glass vials containing 30 symbiotic or aposymbiotic beetles that had been reared under high (60\% $\mathrm{RH}$ ) or low humidity $(30-40 \% \mathrm{RH})$ were incubated for $24 \mathrm{~h}$ in a desiccation chamber as described above and subsequently given another $24 \mathrm{~h}$ to recover under their respective rearing conditions. Control groups were kept for $48 \mathrm{~h}$ under the respective rearing conditions. Afterwards, all beetles from each vial were freeze-killed and extracted for 10 min with $100 \mu \mathrm{L}$ hexane HPLC-grade (Roth, Germany) containing $2 \mu \mathrm{g}$ octadecane (SigmaAldrich, Germany) as internal standard. After removal of beetles, extracts were concentrated to $\sim 30 \mu \mathrm{L}$, and $5 \mu \mathrm{L}$ were analysed on a Varian 450GC gas chromatograph coupled to a Varian 240MS ion-trap mass spectrometer (Agilent Technologies, Böblingen, Germany) using a split/splitless injector at $250^{\circ} \mathrm{C}$ with the purge valve opened after 60s. The GC was equipped with a DB5-ms column (30 m×0.25 mm ID; $0.25 \mu \mathrm{m} d f$;

Agilent, Santa Clara, CA, USA) and programmed from 150 to $320^{\circ} \mathrm{C}$ at $5^{\circ} \mathrm{C} / \mathrm{min}$ with a $5 \mathrm{~min}$. final isothermal hold. Helium was used as carrier gas, with a constant flow rate of $1 \mathrm{ml} / \mathrm{min}$. Mass spectra were recorded using electron ionization (EI-MS) with an ion trap temperature of $90^{\circ} \mathrm{C}$. Data acquisition and quantifications were achieved with MS Workstation Version 6.9.3 Software (Agilent Technologies). Hydrocarbons were identified by retention index and fragmentation pattern in accordance with Howard et al. (1995). CHCs were automatically quantified using the Varian MS Workstation 6.9.3 software with manual correction. For analysis, we calculated total amount of $\mathrm{CHCs}$ per beetle (based on the amount of internal standard), the proportion of saturated $\mathrm{CHCs}$, and a carbon chain length index (sum of the proportions of compounds multiplied by their respective number of carbon atoms).

\section{Statistical procedures}

Symbiont abundance $\left(\Delta \mathrm{C}_{\mathrm{T}}\right.$ (symbiont $16 \mathrm{~s}$ rDNA/host $\left.28 \mathrm{~S} \mathrm{rDNA}\right)$ ), initial test of cuticle melanization and population growth were tested between treatment and control by exact, 2-sided Mann-Whitney-U tests in SPSS 23 (IBM, Armonk, NY).

Influence of symbiont infection, rearing humidity, and in case of $\mathrm{CHC}$ profile also desiccation stress, and their interaction effects was tested with generalized linear models (GLMs) in SPSS 23. For beetle melanization, cuticle diameter of adults and larvae, all CHC measurements and water loss, we used linear scale response models with a normal distribution. For the population size counts, we used a Poisson distribution and a log link function. Model parameters were estimated by the quasi-likelihood method and accepted if the full 
445 factorial model showed a significantly better fit than the intercept-only model (in all cases $p<0.001$ ). Wald $\chi^{2}$ 446 statistics were calculated for the models and single factors. Boxplots were also visualized with SPSS 23. Water

447 loss over time and across treatments was tested with generalized linear models with repeated measures, also 448 in SPSS23 and visualized using the 'ggplot2' (Wickham and Chang, 2016) package in R studio version 3.1.1.

Mortality of O.surinamensis adults was analysed using a Cox mixed effects model with symbiont infection and rearing humidity and a random intercept per replicate population. The analysis was carried out using the package 'coxme' (Therneau, 2012) in R studio version 3.1.1. Survival probability of treatments was plotted based on Kaplan-Meier models using the 'rms' package (Harrell and Frank, 2013).

Survial during juvenile development (measured as percentage of individuals successfully developing from eggs to adults) was compared by manually calculating $\chi^{2}$ homogeneity tests.

\section{Data availability}

Partial symbiont 16S rDNA sequences are deposited in Genbank under accession numbers MF183956MF183966.

\section{Contributions}

T.E. and M.K. designed the project and wrote the manuscript, C.A. and R.P. provided beetle cultures and specimen, N.E., C.G. and T.K. characterized the symbionts of $O$. surinamensis, T.S. performed O.surinamensis larval survival assays, T.E. performed all other experiments and analyzed the data.

\section{Acknowledgements}

463

464

465

466

467

468
M.K. and T.E. acknowledge funding from the Max-Planck-Society. We thank Benjamin Weiss, Dagmar Klebsch and Christiane Stürzbecher for technical assistance.

\section{Competing interests}

The authors declare no competing financial interests.

\section{References (50 + unlimited in Methods only)}

Amann RI, Binder BJ, Olson RJ, Chisholm SW, Devereux R \& Stahl DA. 1990. Combination of 16s rRNATargeted Oligonucleotide Probes with Flow-Cytometry for Analyzing Mixed Microbial-Populations. Appl. Environ. Microbiol. 56: 1919-1925. 
Baele G \& Lemey P. 2013. Bayesian evolutionary model testing in the phylogenomics era: matching model complexity with computational efficiency. Bioinformatics 29: 1970-1979, doi:10.1093/bioinformatics/btt340.

Brumin M, Kontsedalov S \& Ghanim M. 2011. Rickettsia influences thermotolerance in the whitefly Bemisia tabaci B biotype. Insect Sci. 18: 57-66, doi:10.1111/j.1744-7917.2010.01396.x.

Buchner P. 1965. Endosymbiosis of Animals with Plant Microorganisms. New York: John Wiley \& Sons Campbell MA, Van Leuven JT, Meister RC, Carey KM, Simon C \& Mccutcheon JP. 2015. Genome expansion via lineage splitting and genome reduction in the cicada endosymbiont Hodgkinia. Proc. Natl. Acad. Sci. U. S. A. 112: 10192-10199, doi:10.1073/pnas.1421386112.

Cole JR, Wang Q, Fish JA, Chai BL, Mcgarrell DM, Sun YN, Brown CT, Porras-Alfaro A, Kuske CR \& Tiedje JM. 2014. Ribosomal Database Project: data and tools for high throughput rRNA analysis. Nucleic Acids Res. 42: D633-D642, doi:10.1093/nar/gkt1244.

Corbin C, Heyworth ER, Ferrari J \& Hurst GDD. 2017. Heritable symbionts in a world of varying temperature. Heredity 118: 10-20, doi:10.1038/hdy.2016.71.

Crowson RA. 1981. The Biology of the Coleoptera. London, UK: Academic Press

Darriba D, Taboada GL, Doallo R \& Posada D. 2012. jModelTest 2: more models, new heuristics and parallel computing. Nat. Meth. 9: 772-772.

De Souza JD, Devers S \& Lenoir A. 2011. Blochmannia endosymbionts and their host, the ant Camponotus fellah: Cuticular hydrocarbons and melanization. C. R. Biol. 334: 737-741, doi:10.1016/j.crvi.2011.06.008.

Degnan PH, Lazarus AB \& Wernegreen JJ. 2005. Genome sequence of Blochmannia pennsy/vanicus indicates parallel evolutionary trends among bacterial mutualists of insects. Genome Res. 15: 1023-1033, doi:10.1101/Gr.3771305.

Douglas AE. 2009. The microbial dimension in insect nutritional ecology. Funct. Ecol. 23: 38-47, doi:10.1111/j.1365-2435.2008.01442.x.

Drummond A. 2011. Geneious v9.1.5. Auckland, New Zealand: Biomatters Ltd.

Drummond AJ, Ho SYW, Phillips MJ \& Rambaut A. 2006. Relaxed phylogenetics and dating with confidence. PLoS Biol. 4: 699-710, doi:10.1371/journal.pbio.0040088.

Drummond AJ \& Rambaut A. 2007. BEAST: Bayesian evolutionary analysis by sampling trees. BMC Evol. Biol. 7, doi:10.1186/1471-2148-7-214.

Feldhaar H. 2011. Bacterial symbionts as mediators of ecologically important traits of insect hosts. Ecol. Entomol. 36: 533-543, doi:10.1111/j.1365-2311.2011.01318.x. 
504

505

506

507

508

509

510

511

512

513

514

515

516

517

518

519

520

521

522

523

524

525

526

527

528

529

530

531

532

533

534

535

536

Florez LV, Biedermann PHW, Engl T \& Kaltenpoth M. 2015. Defensive symbioses of animals with prokaryotic and eukaryotic microorganisms. Nat. Prod. Rep. 32: 904-936, doi:10.1039/C5NP00010F.

Gibbs AG \& Rajpurohit S. 2010. Cuticular Lipids and Water Balance. In: Bagnères A-G \& Blomquist GJ, editors. Insect Hydrocarbons: Biology, Biochemistry, and Chemical Ecology. Cambridge: Cambridge University Press. p100-120

Gil R, Silva FJ, Zientz E, Delmotte F, Gonzalez-Candelas F, Latorre A, Rausell C, Kamerbeek J, Gadau J, Holldobler B, Van Ham RCHJ, Gross R \& Moya A. 2003. The genome sequence of Blochmannia floridanus: Comparative analysis of reduced genomes. Proc. Natl. Acad. Sci. U. S. A. 100: 9388-9393, doi:10.1073/pnas.1533499100.

Guindon S \& Gascuel O. 2003. A simple, fast, and accurate algorithm to estimate large phylogenies by maximum likelihood. Syst. Biol. 52: 696-704, doi:10.1080/10635150390235520.

Hackman. 1974. Chemistry of the insect cuticle. In: Rockenstein M, editor The Physiology Of Insecta. New York, NY, USA: Academic Press. p215-270

Hagstrum DW, Flinn PW \& Howard RW. 1996. Ecology. In: Hagstrum DW \& Subramanyam B, editors. Integrated Management of Insects in Stored Products. New York, NY, USA: Marcel Dekker. p71-134 Harmon JP, Moran NA \& Ives AR. 2009. Species Response to Environmental Change: Impacts of Food Web Interactions and Evolution. Science 323: 1347-1350, doi:10.1126/science.1167396.

Harrell J \& Frank E. 2013. Rrms: Regression Modeling Strategies. R package version 5.1-0

Heddi A, Grenier AM, Khatchadourian C, Charles H \& Nardon P. 1999. Four intracellular genomes direct weevil biology: Nuclear, mitochondrial, principal endosymbiont, and Wolbachia. Proc. Natl. Acad. Sci. U. S. A. 96: 6814-6819, doi:10.1073/pnas.96.12.6814.

Hoadley RB. 1998. Chemical and Physical Properties of Wood. In: Dardes K \& Rothe A, editors. The Structural Conservation of Panel Paintings. Los Angeles, CA, USA: Getty Publications.

Hosokawa T, Koga R, Tanaka K, Moriyama M, Anbutsu H \& Fukatsu T. 2015. Nardonella endosymbionts of Japanese pest and non-pest weevils (Coleoptera: Curculionidae). Appl. Entomol. Zool. 50: 223-229, doi:10.1007/s13355-015-0326-y.

Howard RW, Howard CD \& Colquhoun S. 1995. Ontogenic and Environmentally-Induced Changes in Cuticular Hydrocarbons of Oryzaephilus surinamensis (Coleoptera, Cucujidae). Ann. Entomol. Soc. Am. 88: 485-495.

Huelsenbeck JP \& Ronquist F. 2001. MRBAYES: Bayesian inference of phylogenetic trees. Bioinformatics 17: 754-755, doi:10.1093/bioinformatics/17.8.754.

Huelsenbeck JP, Ronquist F, Nielsen R \& Bollback JP. 2001. Evolution - Bayesian inference of phylogeny and its impact on evolutionary biology. Science 294: 2310-2314, doi:10.1126/science.1065889. 
537

538

539

540

541

542

543

544

545

546

547

548

549

550

551

552

553

554

555

556

557

558

559

560

561

562

563

564

565

566

567

568

569

Huger A. 1956. Experimentelle Untersuchungen über die künstliche Symbiontenelimination bei Vorratsschädlingen: Rhizopertha dominica F. (Bostrychidae) und Oryzaephilus surinamensis L. (Cucujidae). Z. Morphol. Oekol. Tiere 44: 626-701, doi:10.1007/BF00390698.

Hunt T, Bergsten J, Levkanicova Z, Papadopoulou A, John OS, Wild R, Hammond PM, Ahrens D, Balke M, Caterino MS, Gómez-Zurita J, Ribera I, Barraclough TG, Bocakova M, Bocak L \& Vogler AP. 2007. A Comprehensive Phylogeny of Beetles Reveals the Evolutionary Origins of a Superradiation. Science 318: 1913-1916, doi:10.1126/science.1146954.

Hurst GDD, Bandi C, Sacchi L, Cochrane AG, Bertrand D, Karaca I \& Majerus MEN. 1999. Adonia variegata (Coleoptera: Coccinellidae) bears maternally inherited Flavobacteria that kill males only. Parasitology 118: 125-134, doi:10.1017/S0031182098003655.

Hurst GDD, Hammarton TC, Bandi C, Majerus TMO, Bertrand D \& Majerus MEN. 1997. The diversity of inherited parasites of insects: the male-killing agent of the ladybird beetle Coleomegilla maculata is a member of the Flavobacteria. Genet. Res. 70:1-6, doi:10.1017/S0016672397002838.

Husnik F, Chrudimsky T \& Hypsa V. 2011. Multiple origins of endosymbiosis within the Enterobacteriaceae (gamma-Proteobacteria): convergence of complex phylogenetic approaches. BMC Biol. 9, doi:10.1186/1741-7007-9-87.

Joy JB. 2013. Symbiosis catalyses niche expansion and diversification. Proc. R. Soc. Lond. B Biol. Sci. 280, doi:10.1098/Rspb.2012.2820.

Kleespies RG, Nansen C, Adouhoun T \& Huger AM. 2001. Ultrastructure of bacteriomes and their sensitivity to ambient temperatures in Prostephanus truncatus (Horn). Biocontrol Sci. Technol. 11: 217-232, doi:10.1080/09583150120035648.

Klein A, Schrader L, Gil R, Manzano-Marin A, Florez L, Wheeler D, Werren JH, Latorre A, Heinze J, Kaltenpoth M, Moya A \& Oettler J. 2016. A novel intracellular mutualistic bacterium in the invasive ant Cardiocondyla obscurior. ISME J. 10: 376-388, doi:10.1038/ismej.2015.119.

Klepzig KD, Adams AS, Handelsman J \& Raffa KF. 2009. Symbioses: A Key Driver of Insect Physiological Processes, Ecological Interactions, Evolutionary Diversification, and Impacts on Humans. Environ. Entomol. 38: 67-77, doi:10.1603/022.038.0109.

Koch A. 1931. Die Symbiose von Oryzaephilus surinamensis L. (Cucujidae, Coleoptera). Z. Morphol. Oekol. Tiere 23: 389-424, doi:10.1007/BF00446355.

Koch A. 1936a. Symbiosestudien. I. Die Symbiose des Splintkäfers, Lyctus linearis Goeze. Z. Morphol. Oekol. Tiere 32: 92-136, doi:10.1007/BF00406593.

Koch A. 1936b. Symbiosestudien. II. Experimentelle Untersuchungen an Oryzaephilus surinamensis L. (Cucujidae, Coleopt.). Z. Morphol. Oekol. Tiere 32: 137-180, doi:10.1007/BF00406594. 
Koch A. 1956. The experimental elimination of symbionts and its consequences. Exp. Parasitol. 5: 481-518, doi:10.1016/S0014-4894(56)80008-8.

Kuriwada T, Hosokawa T, Kumano N, Shiromoto K, Haraguchi D \& Fukatsu T. 2010. Biological Role of Nardonella Endosymbiont in Its Weevil Host. PLoS One 5, doi:10.1371/journal.pone.0013101.

Levkanicova Z. 2009. Molecular Phylogeny of the Superfamily Tenebrionoidea (Coleoptera: Cucujiformia). PhD, Palacky Univarsity.

Lo N, Bandi C, Watanabe H, Nalepa C \& Beninati T. 2003. Evidence for cocladogenesis between diverse dictyopteran lineages and their intracellular endosymbionts. Mol. Biol. Evol. 20: 907-913, doi:10.1093/molbev/msg097.

Mansour K. 1934. On the Intracellular Micro-organisms of some Bostrychid Beetles. Q. J. Microsc. Sci. 77: 243-U17.

Mccutcheon JP \& Moran NA. 2010. Functional Convergence in Reduced Genomes of Bacterial Symbionts Spanning 200 My of Evolution. Genome Biol. Evol. 2: 708-718, doi:10.1093/gbe/evq055.

Mccutcheon JP \& Von Dohlen CD. 2011. An Interdependent Metabolic Patchwork in the Nested Symbiosis of Mealybugs. Curr. Biol. 21: 1366-1372, doi:10.1016/j.cub.2011.06.051.

Misof B, Liu SL, Meusemann K, Peters RS, Donath A, Mayer C, Frandsen PB, Ware J, Flouri T, Beutel RG, Niehuis O, Petersen M, Izquierdo-Carrasco F, Wappler T, Rust J, Aberer AJ, Aspock U, Aspock H, Bartel D, Blanke A, Berger S, Bohm A, Buckley TR, Calcott B, Chen JQ, Friedrich F, Fukui M, Fujita M, Greve C, Grobe P, Gu SC, Huang Y, Jermiin LS, Kawahara AY, Krogmann L, Kubiak M, Lanfear R, Letsch H, Li YY, Li ZY, Li JG, Lu HR, Machida R, Mashimo Y, Kapli P, Mckenna DD, Meng GL, Nakagaki Y, Navarrete-Heredia JL, Ott M, Ou YX, Pass G, Podsiadlowski L, Pohl H, Von Reumont BM, Schutte K, Sekiya K, Shimizu S, Slipinski A, Stamatakis A, Song WH, Su X, Szucsich NU, Tan MH, Tan XM, Tang M, Tang JB, Timelthaler G, Tomizuka S, Trautwein M, Tong XL, Uchifune T, WalzI MG, Wiegmann BM, Wilbrandt J, Wipfler B, Wong TKF, Wu Q, Wu GX, Xie YL, Yang SZ, Yang Q, Yeates DK, Yoshizawa K, Zhang Q, Zhang R, Zhang WW, Zhang YH, Zhao J, Zhou CR, Zhou LL, Ziesmann T, Zou SJ, Li YR, Xu X, Zhang Y, Yang HM, Wang J, Wang J, Kjer KM, et al. 2014. Phylogenomics resolves the timing and pattern of insect evolution. Science 346: 763-767, doi:10.1126/science.1257570.

Montllor CB, Maxmen A \& Purcell AH. 2002. Facultative bacterial endosymbionts benefit pea aphids Acyrthosiphon pisum under heat stress. Ecol. Entomol. 27: 189-195, doi:10.1046/j.13652311.2002.00393.x.

Moran NA. 2006. Symbiosis. Curr. Biol. 16: R866-R871, doi:10.1016/j.cub.2006.09.019. 
601

602

603

604

605

606

607

608

609

610

611

612

613

614

615

616

617

618

619

620

621

622

623

624

625

626

627

628

629

630

631

632

Moran NA, Tran P \& Gerardo NM. 2005. Symbiosis and Insect Diversification: an Ancient Symbiont of SapFeeding Insects from the Bacterial Phylum Bacteroidetes. Appl. Environ. Microbiol. 71: 8802-8810, doi:10.1128/aem.71.12.8802-8810.2005.

Muthukrishnan S, Merzendorfer H, Arakane Y \& Kramer KJ. 2012. Chitin Metabolism in Insects. In: Gilbert LI, editor Insect Molecular Biology and Biochemistry. San Diego, CA, USA: Academic Press. p193-235

Nardon P \& Grenier AM 1988. Genetical and Biochemical Interactions Between the Host and its Endocytobiotes in the Weevils Sitophilus (Coleoptere, Curculionidae) and other related species. In: Scannerini S, Smith D, Bonfante-Fasolo P \& Gianinazzi-Pearson V (eds.) Cell to Cell Signals in Plant, Animal and Microbial Symbiosis. Berlin, Germany: Springer-Verlag.

Nations FaaOOTU. 1990. Roots, tubers, plantains and bananas in human nutrition. food \& Agriculture Organization

Oliver KM \& Martinez AJ. 2014. How resident microbes modulate ecologically important traits of insects. Curr. Opin. Insect Sci. 4: 1-7, doi:10.1016/j.cois.2014.08.001.

Patino-Navarrete R, Moya A, Latorre A \& Pereto J. 2013. Comparative Genomics of Blattabacterium cuenoti: The Frozen Legacy of an Ancient Endosymbiont Genome. Genome Biol. Evol. 5: 351-361, doi:10.1093/gbe/evt011.

Pfaffl MW. 2001. A new mathematical model for relative quantification in real-time RT-PCR. Nucleic Acids Res. 29, doi:10.1093/nar/29.9.e45.

Quast C, Pruesse E, Yilmaz P, Gerken J, Schweer T, Yarza P, Peplies J \& Glockner FO. 2013. The SILVA ribosomal RNA gene database project: improved data processing and web-based tools. Nucleic Acids Res. 41: D590-D596, doi:10.1093/nar/gks1219.

Rasband WS. 1997-2016. ImageJ. Bethesda, Maryland, USA: U. S. National Institutes of Health Ronquist F \& Huelsenbeck JP. 2003. MrBayes 3: Bayesian phylogenetic inference under mixed models. Bioinformatics 19: 1572-1574, doi:10.1093/bioinformatics/btg180.

Russell JA \& Moran NA. 2006. Costs and benefits of symbiont infection in aphids: variation among symbionts and across temperatures. Proc. R. Soc. Lond. B Biol. Sci. 273: 603-610, doi:10.1098/rspb.2005.3348.

Sabree ZL, Kambhampati S \& Moran NA. 2009. Nitrogen recycling and nutritional provisioning by Blattabacterium, the cockroach endosymbiont. Proc. Natl. Acad. Sci. U. S. A. 106: 19521-19526, doi:10.1073/pnas.0907504106.

Silva FJ \& Santos-Garcia D. 2015. Slow and Fast Evolving Endosymbiont Lineages: Positive Correlation between the Rates of Synonymous and Non-Synonymous Substitution. Front. Microbiol. 6, doi:10.3389/Fmicb.2015.01279. 
633

634

635

636

637

638

639

640

641

642

643

644

645

646

647

648

649

650

651

652

653

654

655

656

657

658

659

660

661

662

663

664

665

Souci SW, Fachmann W \& Kraut H. 2009. Lebensmitteltabelle für die Praxis. Stuttgart: Wissenschaftliche Verlagsgesellschaft

Sudakaran S, Kost C \& Kaltenpoth M. 2017. Symbiont Acquisition and Replacement as a Source of Ecological Innovation. Trends Microbiol., doi:10.1016/j.tim.2017.02.014.

Sudakaran S, Retz F, Kikuchi Y, Kost C \& Kaltenpoth M. 2015. Evolutionary transition in symbiotic syndromes enabled diversification of phytophagous insects on an imbalanced diet. ISME J. 9: 2587-2604, doi:10.1038/ismej.2015.75.

Takiya DM, Tran PL, Dietrich CH \& Moran NA. 2006. Co-cladogenesis spanning three phyla: leafhoppers (Insecta: Hemiptera: Cicadellidae) and their dual bacterial symbionts. Mol. Ecol. 15: 4175-4191, doi:10.1111/j.1365-294X.2006.03071.X.

Therneau T. 2012. Coxme: Mixed Effects Cox Models. R package version 2.2-5

Thomas MC \& Leschen RaB. 2009. Silvanidae Kirby, 1837. In: Leschen RaB, Beutel RG \& Lawrence JF, editors. Handbook of Zoology - Coleoptera, Beetles. Berlin, Germany: De Gruyter. p346-350

Van Den Bosch TJM \& Welte CU. 2017. Detoxifying symbionts in agriculturally important pest insects. Microb. Biotechnol. 10: 531-540, doi:10.1111/1751-7915.12483.

Van Leuven JT, Meister RC, Simon C \& Mccutcheon JP. 2014. Sympatric Speciation in a Bacterial Endosymbiont Results in Two Genomes with the Functionality of One. Cell 158: 1270-1280, doi:10.1016/j.cell.2014.07.047.

Vigneron A, Masson F, Vallier A, Balmand S, Rey M, Vincent-Monegat C, Aksoy E, Aubailly-Giraud E, Zaidman-Remy A \& Heddi A. 2014. Insects Recycle Endosymbionts when the Benefit Is Over. Curr. Biol. 24: 2267-2273, doi:10.1016/j.cub.2014.07.065.

Weisburg WG, Barns SM, Pelletier DA \& Lane DJ. 1991. 16S Ribosomal DNA Amplification for Phylogenetic Study. J. Bacteriol. 173: 697-703, doi:10.1128/jb.173.2.697-703.1991.

Weller R, Glockner FO \& Amann R. 2000. 16S rRNA-targeted oligonucleotide probes for the in situ detection of members of the phylum Cytophaga-Flavobacterim-Bacteroides. Syst. Appl. Microbiol. 23: 107114, doi:10.1016/S0723-2020(00)80051-X.

Wernegreen JJ. 2012. Mutualism meltdown in insects: bacteria constrain thermal adaptation. Curr. Opin. Microbiol. 15: 255-262, doi:10.1016/j.mib.2012.02.001.

Wickham H \& Chang W. 2016. Create Elegant Data Visualisations Using the Grammar of Graphics. R package version 2.2.1

Wu D, Daugherty SC, Van Aken SE, Pai GH, Watkins KL, Khouri H, Tallon L, Zaborsky JM, Dunbar HE, Tran PL, Moran NA \& Eisen JA. 2006. Metabolic Complementarity and Genomics of the Dual Bacterial Symbiosis of Sharpshooters. PLoS Biol. 4: e188, doi:10.1371/journal.pbio.0040188. 
bioRxiv preprint doi: https://doi.org/10.1101/182725; this version posted August 30, 2017. The copyright holder for this preprint (which was not certified by peer review) is the author/funder. All rights reserved. No reuse allowed without permission.

666 Yilmaz P, Parfrey LW, Yarza P, Gerken J, Pruesse E, Quast C, Schweer T, Peplies J, Ludwig W \& Glockner FO. 667 2014. The SILVA and "All-species Living Tree Project (LTP)" taxonomic frameworks. Nucleic Acids 668 Res. 42: D643-D648, doi:10.1093/nar/gkt1209.

669 
670 Table 1 Statistical test results of generalized linear and cox-mixed effects models describing the influence of 671 symbiont presence/absence, environmental humidity and acute desiccation stress on variable beetle 672 parameters. Tests are in order as they appear in the manuscript. $\chi^{2}=\chi^{2}$ Wald factors significantly influencing 673 a parameter are highlighted in bold.

\begin{tabular}{|c|c|c|c|c|c|c|c|c|}
\hline & test & $\begin{array}{l}\text { symbiont } \\
\text { presence/ } \\
\text { absence }\end{array}$ & $\begin{array}{l}\text { Environ- } \\
\text { mental } \\
\text { humidity }\end{array}$ & $\begin{array}{l}\text { acute } \\
\text { dessication } \\
\text { stress }\end{array}$ & $\begin{array}{l}\text { symbiont* } \\
\text { humidity }\end{array}$ & $\begin{array}{l}\text { symbiont* } \\
\text { stress }\end{array}$ & $\begin{array}{l}\text { humidity* } \\
\text { stress }\end{array}$ & $\begin{array}{l}\text { all three } \\
\text { factors }\end{array}$ \\
\hline Melanization & GLM & $\begin{array}{l}\chi^{2}=92.3, \\
\text { d.f. }=1, \\
p<0.001\end{array}$ & $\begin{array}{l}\chi^{2}=94.1, \\
\text { d.f.=1, } \\
p<0.001\end{array}$ & & $\begin{array}{l}\chi^{2}=0.5 \\
\text { d.f. }=1, \\
p=0.488\end{array}$ & & & \\
\hline $\begin{array}{l}\text { Cuticle } \\
\text { thickness }\end{array}$ & GLM & $\begin{array}{l}\chi^{2}=52.5, \\
\text { d.f.=1, } \\
p<0.001\end{array}$ & $\begin{array}{l}\chi^{2}=4.5, \\
\text { d.f.=1, } \\
p=0.034\end{array}$ & & $\begin{array}{l}\chi^{2}=0.837 \\
\text { d.f. }=1 \\
p=0.360\end{array}$ & & & \\
\hline $\begin{array}{l}\text { Endocuticle } \\
\text { thickness }\end{array}$ & GLM & $\begin{array}{l}\chi^{2}=32.6, \\
\text { d.f. }=1, \\
p<0.001\end{array}$ & $\begin{array}{l}\chi^{2}=6.8 \\
\text { d.f. }=1, \\
p=0.009\end{array}$ & & $\begin{array}{l}\chi^{2}=1.7, \\
\text { d.f.=1, } \\
p=0.197\end{array}$ & & & \\
\hline $\begin{array}{l}\text { Exocuticle } \\
\text { thickness }\end{array}$ & GLM & $\begin{array}{l}\chi^{2}=49.5, \\
\text { d.f. }=1, \\
p<0.001\end{array}$ & $\begin{array}{l}\chi^{2}=0.07, \\
\text { d.f. }=1, \\
p=0.790\end{array}$ & & $\begin{array}{l}\chi^{2}=0.04, \\
\text { d.f. }=1, \\
p=0.843\end{array}$ & & & \\
\hline $\begin{array}{l}\text { Larval cuticle } \\
\text { thickness }\end{array}$ & GLM & $\begin{array}{l}\chi^{2}=17.8, \\
\text { d.f. }=1, \\
p<0.001\end{array}$ & $\begin{array}{l}\chi^{2}=0.2, \\
\text { d.f. }=1 \\
p=0.621\end{array}$ & & 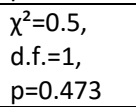 & & & \\
\hline $\begin{array}{l}\text { Total CHC } \\
\text { amounts }\end{array}$ & GLM & $\begin{array}{l}\chi^{2}=14.6 \\
\text { d.f.=1, } \\
p<0.001\end{array}$ & $\begin{array}{l}\chi^{2}=83.5, \\
\text { d.f.=1, } \\
p<0.001\end{array}$ & $\begin{array}{l}\chi^{2}=3.5 \\
\text { d.f.=1, } \\
p=0.061\end{array}$ & $\begin{array}{l}\chi^{2}=6.2, \\
\text { d.f.=1, } \\
p=0.013\end{array}$ & $\begin{array}{l}\chi^{2}=9.2, \\
\text { d.f.=1, } \\
p=0.002\end{array}$ & $\begin{array}{l}\chi^{2}=0.7, \\
\text { d.f.=1, } \\
p=0.391\end{array}$ & $\begin{array}{l}\chi^{2}=5.4, \\
\text { d.f. }=1, \\
p=0.02\end{array}$ \\
\hline $\begin{array}{l}\text { Proportion } \\
\text { unsaturated } \\
\mathrm{CHCs}\end{array}$ & GLM & $\begin{array}{l}\chi^{2}=14.6, \\
\text { d.f. }=1, \\
p<0.001\end{array}$ & $\begin{array}{l}\chi^{2}=83.5, \\
\text { d.f. }=1, \\
p<0.001\end{array}$ & $\begin{array}{l}\chi^{2}=4.8, \\
\text { d.f. }=1, \\
p=0.029\end{array}$ & 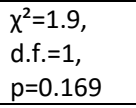 & 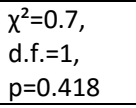 & $\begin{array}{l}\chi^{2}=5.9 \\
\text { d.f. }=1 \\
p=0.015\end{array}$ & $\begin{array}{l}\chi^{2}=0.8 \\
\text { d.f. }=1 \\
p=0.366\end{array}$ \\
\hline $\begin{array}{l}\text { Average } \mathrm{CHC} \\
\text { chain length }\end{array}$ & GLM & $\begin{array}{l}\chi^{2}=13.3, \\
\text { d.f. }=1, \\
p<0.001\end{array}$ & $\begin{array}{l}\chi^{2}=0.02, \\
\text { d.f. }=1 \\
p=0.903\end{array}$ & 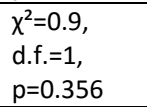 & 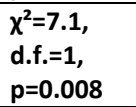 & 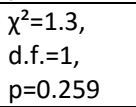 & 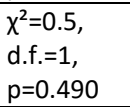 & $\begin{array}{l}\chi^{2}=0.3, \\
\text { d.f. }=1, \\
p=0.567\end{array}$ \\
\hline Water loss & $\begin{array}{l}\text { repeated } \\
\text { measures GLM }\end{array}$ & $\begin{array}{l}\chi^{2}=35.8, \\
\text { d.f. }=1, \\
p<0.001\end{array}$ & 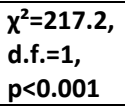 & & $\begin{array}{l}\chi^{2}=0.6, \\
\text { d.f. }=1 \\
p=0.449\end{array}$ & & & \\
\hline Mortality & $\begin{array}{l}\text { Cox mixed- } \\
\text { effects model }\end{array}$ & $\begin{array}{l}z=-2.11 \\
p=0.034\end{array}$ & $\begin{array}{l}\mathrm{z}=-1.22 \\
\mathrm{p}=0.220\end{array}$ & & $\begin{array}{l}z=0.73 \\
p=0.470\end{array}$ & & & \\
\hline $\begin{array}{l}\text { Population } \\
\text { growth }\end{array}$ & GLM & $\begin{array}{l}\chi^{2}=431.3, \\
\text { d.f. }=1, \\
p<0.001\end{array}$ & $\begin{array}{l}\chi^{2}=926.5, \\
\text { d.f. }=1, \\
p<0.001\end{array}$ & & $\begin{array}{l}\chi^{2}=74.1 .1, \\
\text { d.f. }=1, \\
p<0.001\end{array}$ & & & \\
\hline
\end{tabular}




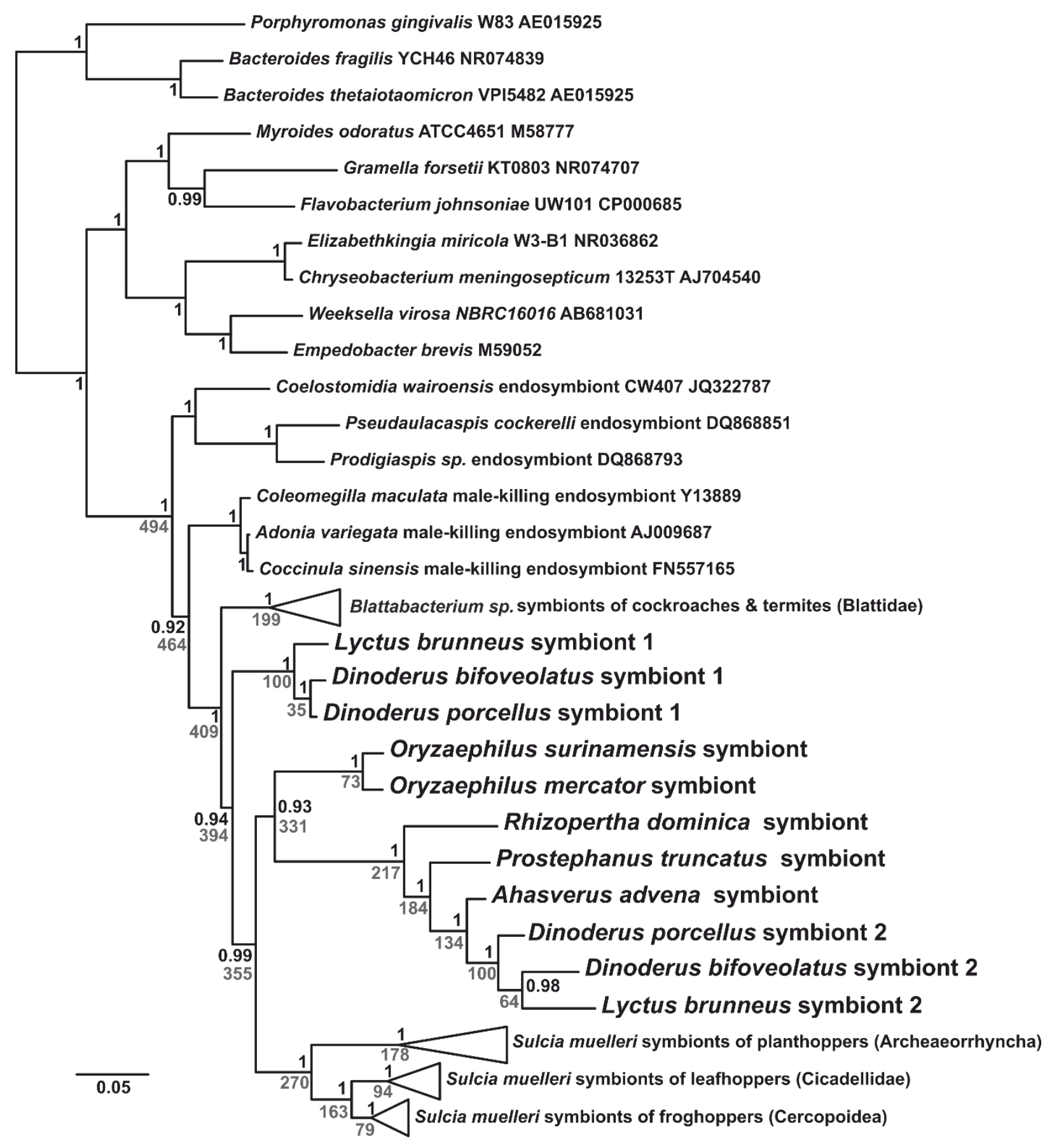

677 Figure 1 Phylogenetic placement of intracellular symbionts in silvanid and bostrichid grain pest beetles within the Bacteroidetes, and their close association to endosymbionts of cockroaches and cicadas. The phylogeny was reconstructed using Bayesian inference, and black node values represent Bayesian posteriors. Grey values represent mean node ages in Mya, based on a phylogenetic dating analysis with the age of Blattabacterium and Sulcia as calibration points. 

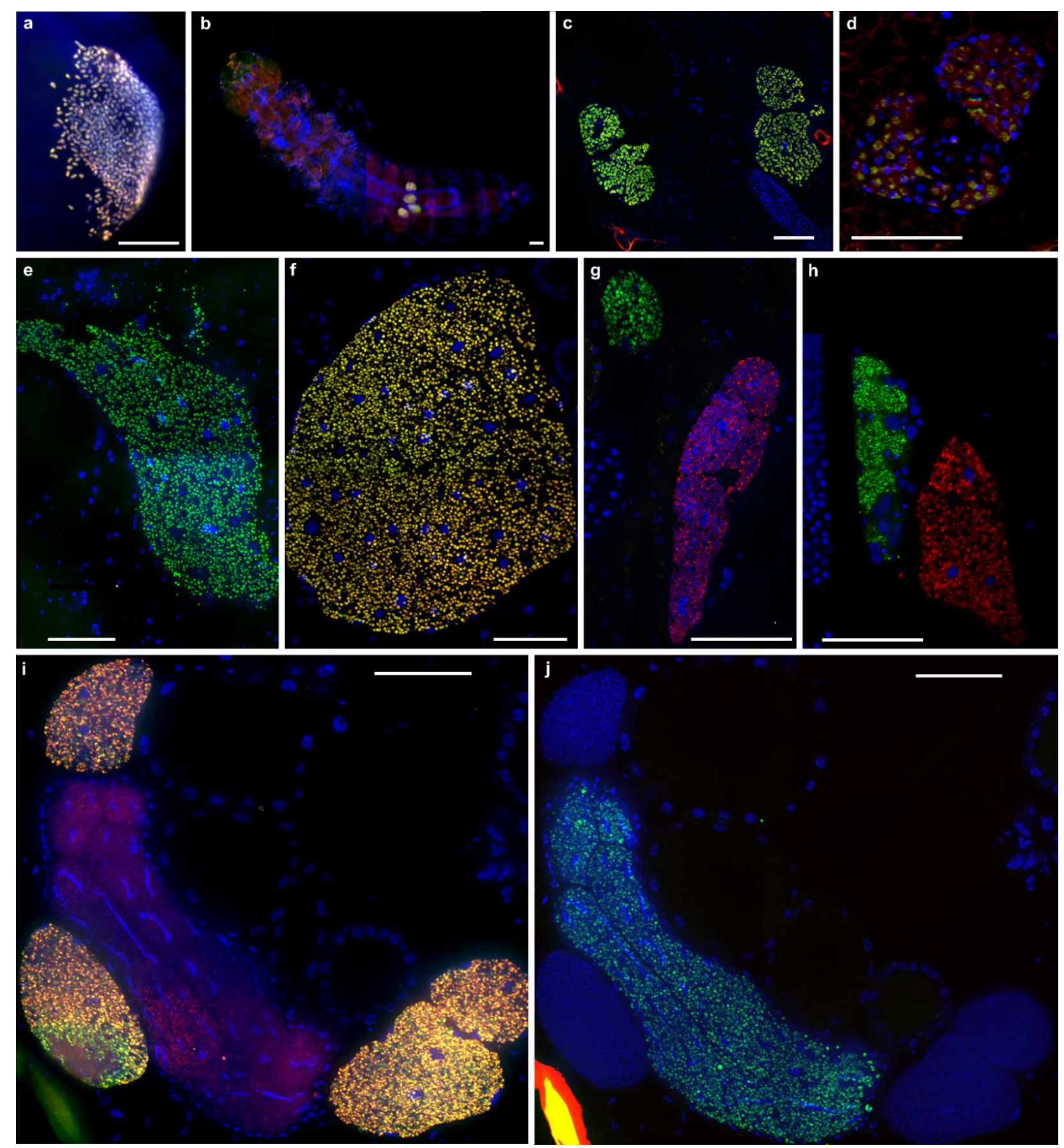

Figure 2 Bacteroidetes symbiont localization in silvanid and bostrichid beetle bacteriomes. Whole mount

Fluorescence in situ hybridization (FISH) of $O$. surinamensis (a) egg, (b) larva, and (c) a longitudinal section of an adult female stained with EUB338-Cy3 (red) and OsurSym16S-Cy5 (green). (d) Cross section of an $A$. advena adult stained with Eub338-Cy3 and CFB563-Cy5. Longitudinal sections of (e) $R$. dominica and (f) $P$. truncatus adults, stained with EUB338-Cy3 (red; did not work in e) and Bostrichidae_Sym2-Cy5 (green), of adult (f) D. bifoveolatus and (g) D. porcellus, stained with Bostrichidae_Sym1-Cy3 (red) and 
a

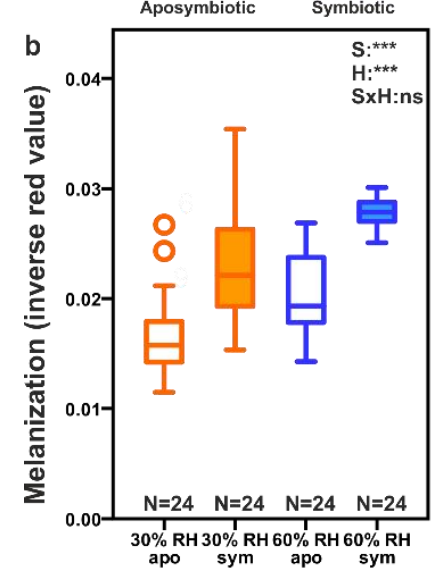

c
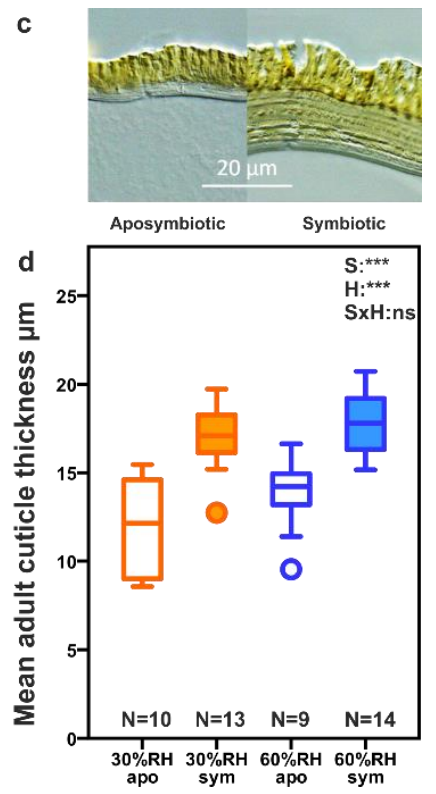

693 Figure 3 Melanization and cuticle thickness of symbiotic and aposymbiotic $O$. surinamensis adults. (a)

694 Photographs of 2 day old aposymbiotic and symbiotic 0. surinamensis adults and (b) melanization measured 695 as thorax coloration of aposymbiotic and symbiotic adults reared at different humidities. (c) Ventral, 696 thoracal cuticle sections of aposymbiotic and symbiotic O.surinamensis adults and (d) cuticle thickess of 697 aposymbiotic and symbiotic adults reared at different humidities. Both symbiont presence (S) and 698 environmental humidity $(H ; G L M, p<0.001)$, but not their interaction $\left(S^{*} H ; G L M, p>0.05\right)$ had a highly 699 significant influence on cuticle melanization and thickness. Boxplots show medians, quartiles and 700 minima/maxima. Sample size is given under each box. Filled boxes represent symbiotic and empty ones aposymbiotic beetles, orange boxes indicate rearing at $30 \% \mathrm{RH}$, blue ones at $60 \% \mathrm{RH}$ 
a

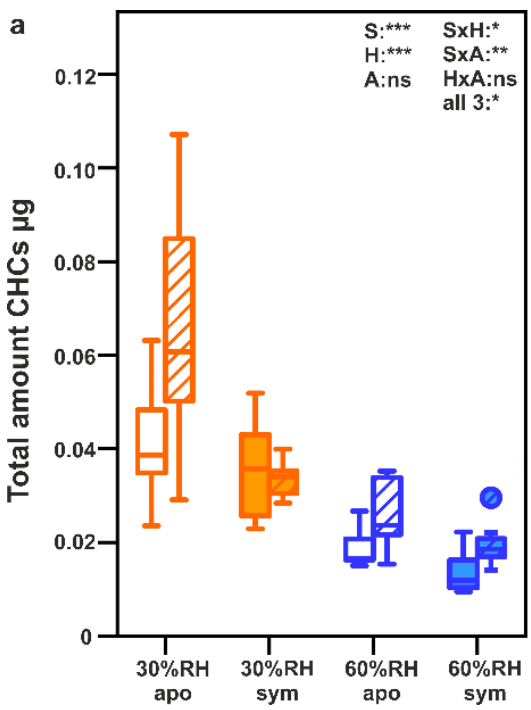

b

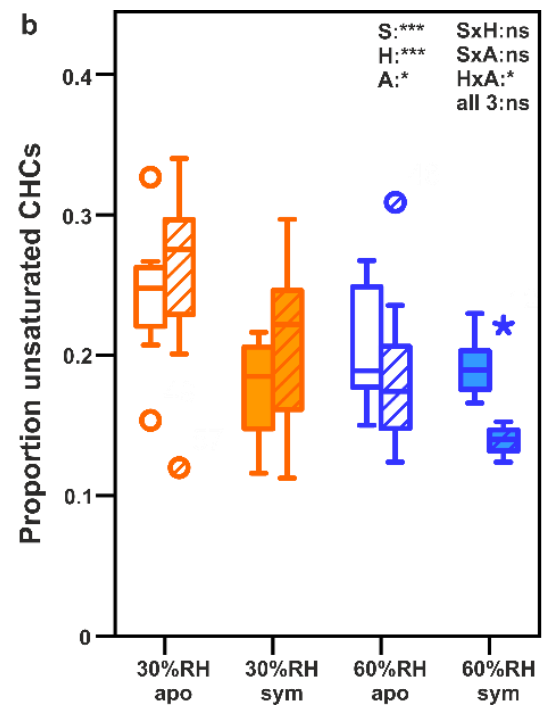

C

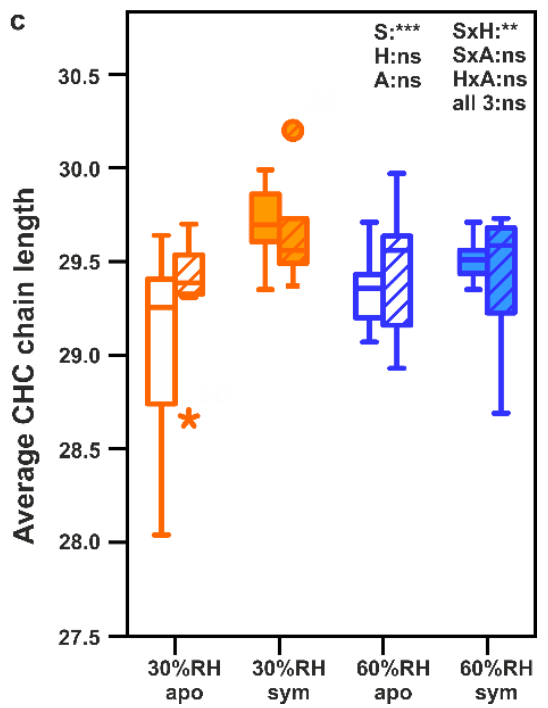

703

704

705

706

707

708

709

710

711

712

713

Figure 4 Rapid desiccation hardening (changes in the cuticular hydrocarbon profile) of $O$. surinamensis as a response to symbiont loss, environmental humidity and acute desiccation stress. (a) Total amounts of cuticular hydrocarbons per beetle (average calculated from 30 pooled beetle extracts), (b) proportion of unsaturated hydrocarbons and (c) average hydrocarbon chain length show physiological counteradaptations of beetles to long-term exposure to low environmental humidity, but especially to acute desiccation stress. Statistical results report on different factors and their interaction affecting $\mathrm{CHC}$ parameters (GLM, $\mathrm{S}=$ symbiont presence, $\mathrm{H}=$ =environmental humidity, $\mathrm{A}=$ acute desiccation stress, ***: $p<0.001 ;^{* *}: p<0.01 ;^{*}: p<0.05$, n.s.: $p \geq 0.05$ ). Filled boxes represent symbiotic and empty ones aposymbiotic beetles, orange boxes indicate rearing at $30 \% \mathrm{RH}$, blue ones at $60 \% \mathrm{RH}$, and hatched boxes show the respective changes after acute desiccation stress. 

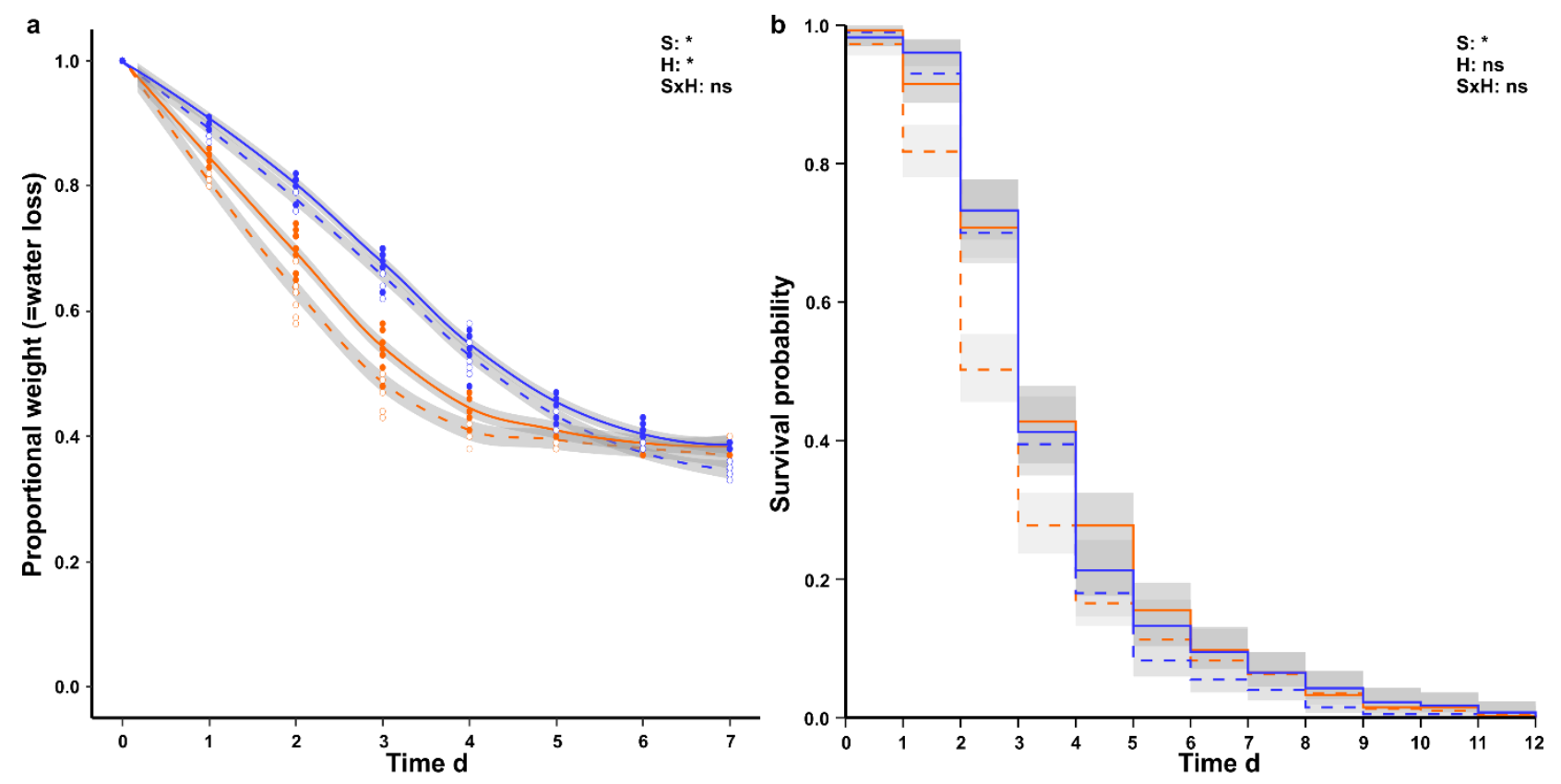

Figure 5 Water loss and survival of $O$. surinamensis adults under acute desiccation stress. (a) Water loss is significantly influenced by symbiont presence as well as rearing humidity $(\mathrm{S}, \mathrm{H} ; \mathrm{GLM}, \mathrm{p}<0.05)$, but not their interaction ( $\left.\mathrm{S}^{*} \mathrm{H} ; \mathrm{GLM}, \mathrm{p}>0.05\right)$, whereas (b) mortality is only significantly influenced by symbiont presence ( $\mathrm{S}$; Cox Mixed-Effect Model, $\mathrm{p}<0.05$ ). Lines show mean, and shaded areas $99 \%$ confidence intervals of (a) 50 pooled beetles for eight replicate populations per treatment and (b) 50 individual beetles from eight replicate populations per treatment. Continuous lines represent symbiotic and dashed lines aposymbiotic beetles, orange lines indicate rearing at $60 \% \mathrm{RH}$, blue lines at $30 \% \mathrm{RH}$

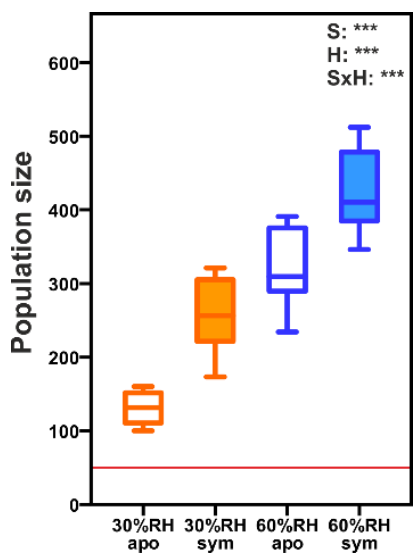

Figure 6 Population growth of O.surinamensis over three months from starting populations of 50 beetles. Symbiont presence, environmental humidity and their interaction have a significant influence on population growth ( $\left.\mathrm{S}, \mathrm{H}, \mathrm{S}^{*} \mathrm{H} ; \mathrm{GLM}, \mathrm{p}<0.001\right)$. The red line indicates the initial population size. Boxplots show median, quartiles, and minimum/maximum of eight replicate populations per treatment. Filled boxes represent symbiotic and empty ones aposymbiotic beetles, orange boxes indicate rearing at $30 \% \mathrm{RH}$, blue ones at $60 \%$ 